\title{
SEED HARVESTING PROPERTIES OF CORN HYBRIDS UNDER TWO-STAGE SEPARATION
}

\author{
MYKOLA KYRPA, DENYS KOVALOV, SVITLANA SKOTAR*, YULIA BAZILIEVA, \\ OKSANA LUPIT'KO
}

\begin{abstract}
State Establishment Institute of Grain Crops of National Academy Agrarian Sciences of Ukraine, Dnipro, Ukraine
\end{abstract}

KYRPA, M. - KOVALOV, D. - SKOTAR, S. - BAZILIEVA, Y. - LUPIT'KO, O.: Seed harvesting properties of corn hybrids under two-stage separation. Agriculture (Pol'nohospodárstvo), vol. 66, no. 3, pp. 118-127.

\begin{abstract}
The objective of this experiment was to identify the effects of two-stage separation of a mixture of corn hybrid seeds to their fractional structure, sawing qualities, and harvesting properties. Research materials were seeds from different ripeness groups of selection in the State Establishment Institute of Grain Crops of National Academy Agrarian Sciences of Ukraine. The research included the laboratory modeling of the seed-separation process in the regimes of sieve separation which was done by features of the linear dimension of a seed. The separation process had two stages - the first stage and the second stage. At the first stage, this mixture of seeds was divided into two components with approximately similar capacity. At the first stage of choice, separate surfaces depended on the shape of the seed and the surface could have holes with different dimension sizes (round holes with a definite diameter or oblong with definite width and length). At the second stage, each component of the seed mixture was divided into fractions of necessary quantity, they had different shapes and linear dimensions of a seed. In researches, it was determined output and weight of 1,000 seeds as the main technic-technological indexes of the seed separation process, laboratory, and field germination, and yield capacity of fractions for corn seeds as the main indexes of quality. It was established that the two-stage method of division of the seed mass into fractions by feature "width of caryopsis" was the most effective for the separation of sowing materials of corn seeds. The indicated method provided the output of high-quality seeds of hybrid Svitiaz' for the first sowing group within $68.8-81.9 \%$, for the second sowing group $66.6-81.2 \%$ by years of researches. Separation in a two-stage regime with a division of seed mixture at the finishing phase of the seed separator work by feature "thickness of caryopsis" provided the formation of more uniform seed fractions.
\end{abstract}

Key words: a mixture of corn seeds, sorting-calibration, a dimension of sieves, sowing properties

During harvesting output material of corn, seeds are a complicated mixture that has different components. First of all, these components include seeds of the main crop and other cultivated and wild plants and also admixtures of organic and mineral nature. Basic corn seeds can have different qualities by their shape, size, weight, colour of some seeds, and also by their sowing and harvesting properties. So, separation helps to stand out the most qualitative seeds with high sorting, sowing, and harvesting proper- ties. Herewith separation independence on a state of a mixture can be carried out in the regimes: cleaning-sorting-calibration with keeping definite technic-technological norms. A search for ways to raise the leveling of seed fractions for sowing material is always troubled by scientists (Shearer et al. 2000). It is known seed is considered homogeneous by the quality if it has an output of $80 \%$ had more from two adjoining sieves. So the first task was to establish homogeneity of researched material. 
There are known valid separation methods of corn hybrids seeds which include the distribution of output mixture into fractions with different sizes and shapes of a seed (Kyrpa \& Skotar 2011; Kyrpa \& Kovalov 2018). However such methods lead to incomplete distribution because seed admixtures of other sizes and shapes stay in different fractions. Incomplete distribution appears because there is a layer of seeds on the separate surfaces which stays dissimilar during the separation process (Telengator et al. 1972; Demin et al. 1968). That's why the important task is the optimization of separate processes taking into account technic-technological features and physic-mechanical properties of corn seeds (Kyrpa \& Skotar 2007; Enayatgholizadeh et al. 2012). Significantly it's noted that the process of the separation of corn seeds is more difficult and more intensive in comparison with the separation of other crops. It is consists of consistent practicable operations such as cleanness, homogeneity, and leveling of seeds. It must be noted the separation process of corn seeds is more difficult and intensive according to the separation of other crops. It is completed with the following working actions namely: cleaning, sorting, and calibration independence on quality, cleanness, homogeneity, and leveling.

Each operation aims is to improve the quality of sowing material indefinite direction. So, cleaning serves for picking out different admixtures from the main mass of seeds: dust and grain. Sorting is for forming sowing fractions of seeds with different qualities. Calibration is for leveling of sowing fraction by coarseness i.e., by features of size and weight of seeds (Soares et al. 2013). The last operation is realized, as a rule, in-plant conditions and needs special machines, more complicated equipment, additional expenditures of electricity.

From all indicated operations, sorting-calibration is realized by typical technic-technological schemes and features of sieving and it has the largest influence on the quality of seeds (Kaliniewicz \& Tylek 2019). Such type of separation is realized by typical schemes on the work elements (sieves), which are placed independently from physic-mechanical properties of different corn hybrids and peculiarities of their harvesting (Bratoev 2014). Using the main features - width and thickness of seeds without their influence on the bolting process and seed quality also refers to the typical approach. So we researched a new sorting method of a seed mixture in regime two-stage separation with its following division into sowing fractions and taking into account the physical-mechanical properties of the seed and indexes of its quality.

The aim of the work was to establish the influence of a new two-stage separation of corn hybrid seed mixture for their fractional structure, sowing qualities, and harvesting properties.

For the achievement of the aim, it was expected to determine regularities of influence for separate methods with different features on output and seed quality, to define the fractional structure of corn hybrids, and also to find out peculiarities of the process of separation in the regime of seed calibration on different sieves.

\section{MATERIAL AND METHODS}

The researching material was seeds of corn hybrids from the different mature group of selection State Establishment Institute of cereal crops of National Academy Agricultural Sciences of Ukraine. The results of the research are presented by the example of medium-early corn hybrid DN Svitiaz' and mid-season - DN Demetra.

The hybrid DN Svitiaz' is a simple interlinear hybrid with FAO 250. Seeds of the presented hybrid have yellow-orange colour, odontoid rounded shape with a weight of 1,000 seeds $300-320 \mathrm{~g}$. Hybrids DN Demetra is a simple modified hybrid FAO 300. It has yellow seeds with an odontoid shape. The weight of 1,000 seeds is $300-330 \mathrm{~g}$ (Catalogue of sorts and hybrids 2017).

The methodology of the research included laboratory modeling of seed process separation in regimes of sieve separation which was realized by features of the linear dimension of a seed. During researches, $2 \mathrm{~kg}$ of seeds of each hybrid was used. These two hybrids were chosen because they characterized definite groups of mature (FAO 250, FAO 300). In researches, chosen hybrids were separated apart. Sowing was realized by the experimental plan according to the program of the researches. So, seeds with a weight $200 \mathrm{~g}$ were sep- 
arating for 3 minutes on the laboratory separator i.e. methods are reproduced absolutely. Each separation which included sieve sowing was realized in two-times recurrence for 3 years of researches. The separation process consisted of two component parts - first and second. At the first stage, the seed mixture was divided into two components nearly with the same capacity. At the first stage choice of a separate surface depended on the shape of a seed namely a surface could have holes with different types of size (round holes with a definite diameter or oblong ones with definite width and length). At the second stage, each component of the seed mixture was divided into fractions of the needed quantity with different shapes and linear dimensions of a seed. The results of separation were estimated by different indications i.e. output and weight of 1,000 seeds (Abdipour et al. 2016), which are the main technic-technological features of the process of grain separation by low method (SSTU 4138-2002). Also, it was determined laboratory germination by a cold test for seeds of different fractions according to methodologies of state standard for valuing of quality for sowing material (SSTU 4138-2002), and also field one by methods worked out by SE Institute of Grain Crops of NAAS (Kazakov 1987). In researches, statistical parameters were calculated affirming data adequacy of research results by known mathematical methods. They included methods by the or a form of electronic tables EXEL (Lesnikova \& Kharchenko 2002).

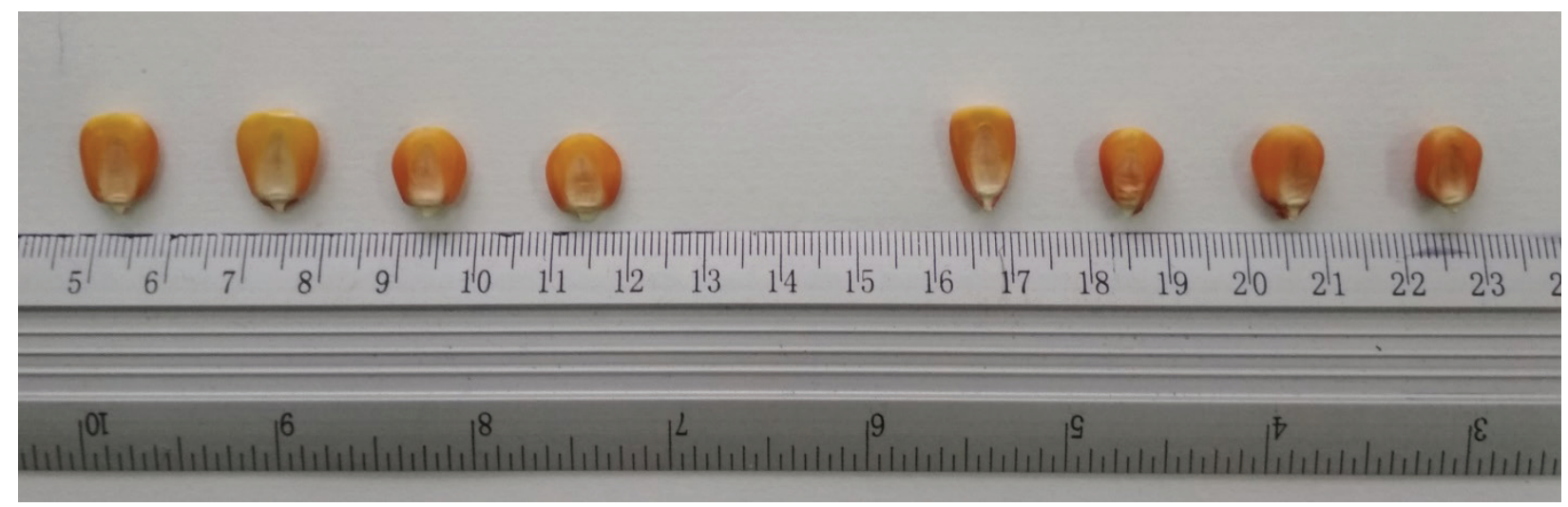

Figure 1. Seeds of the first and second sowing groups of the hybrid DN Demetra On the left in the figure the first sowing group of the hybrid DN Demetra is shown, it's marked out by feature "width of caryopsis" (triage Ø $9.0 \mathrm{~mm}$ ), on the right - the sowing group (walk Ø $9.0 \mathrm{~mm}$ ).

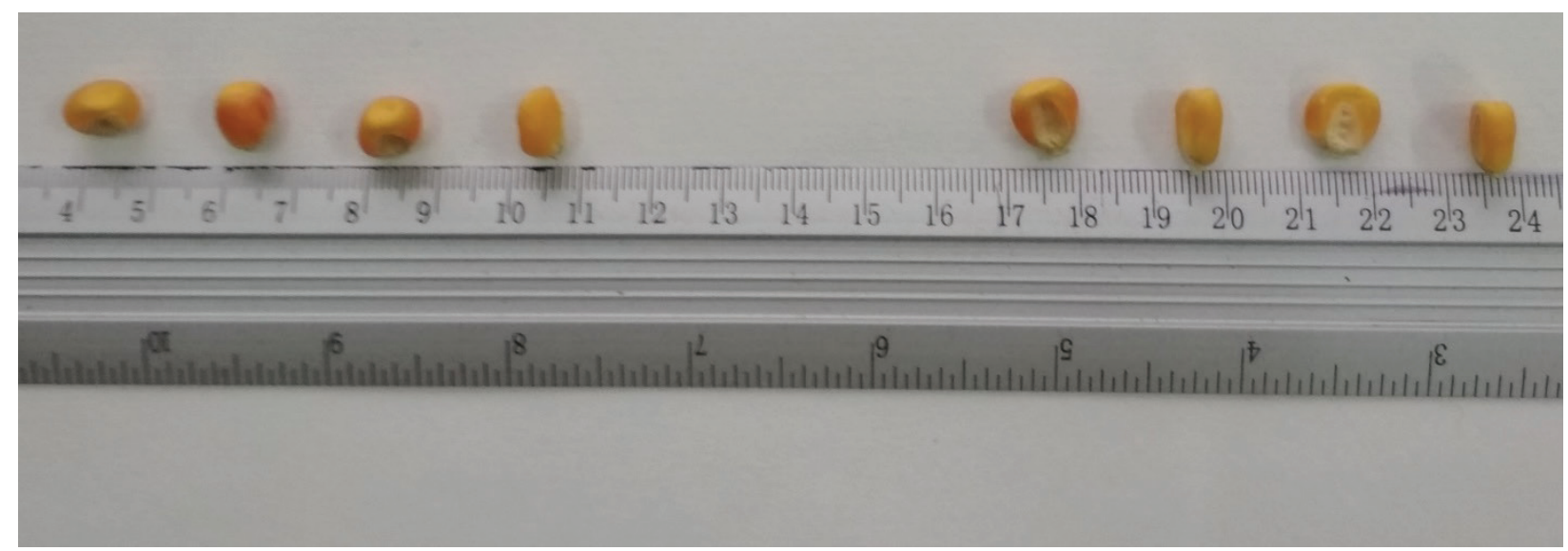

Figure 2. Seeds of the first and second sowing groups of the hybrid DN Svitiaz

On the left in the figure the first sowing group of the hybrid DN Svitiaz' is shown, it's marked out by feature "thickness of caryopsis" (triage $\neq 5.5 \mathrm{~mm}$ ), on the right - the sowing group (walk $\neq 5.5 \mathrm{~mm}$ ). 


\section{RESULTS AND DISCUSSION}

The formation of seed fractions of presented hybrids was on the sieves by features "width" and "thickness" of caryopsis according to the method of typical separation (Table 1,2). The output of fractions by hybrids depended on the shape and size of a seed. So, the output of coarse and fine fractions in the hybrid DN Svitiaz' was almost similar - 17.9 and $17.3 \%$ accordingly. It is explained that the seeds of this hybrid have an oblong-odontoid shape. The output of coarse and fine fractions in hybrid DN Demetra was different a little, namely $10.1-14.4 \%$ accordingly, so the caryopsis of this hybrid has a flat, odontoid shape.

As far as the main output of seeds conditionally taken medium fraction on the sieves with round and oblong holes was less than $80 \%$, namely $64.8-75.5$ and 58.7-73.2\% accordingly. Researching of taken sowing groups and their fractions by a new method of separation was wholly justifiable.

The new method was realized by the following way: the first seed separator divided the mixture into two groups of sowing material in the regime of triage and walk of seeds on the separate sieves; another seed separator (one or two) divided each group into a given number of sowing fractions (there were three fractions in our researches). At the first stage, a separate sieve could be with round holes and with oblong ones (sieves were chosen for two sowing groups with nearly similar output). In our researches hybrids DN Demetra has divided into two sowing

$\mathrm{T}$ a b 1 e 1

Peculiarities of formation fractions of corn seed hybrids in regime of sieve separation (2017-2019) [\%]

\begin{tabular}{|c|c|c|c|c|c|c|}
\hline \multirow{4}{*}{ Years } & \multicolumn{6}{|c|}{ Hybrids } \\
\hline & \multicolumn{3}{|c|}{ DN Demetra } & \multicolumn{3}{|c|}{ DN Svitiaz } \\
\hline & \multicolumn{6}{|c|}{ Sieves diameter $[\mathrm{mm}]$} \\
\hline & $\begin{array}{c}\varnothing 9.5-10.0 \\
\text { triage }\end{array}$ & $\begin{array}{l}\varnothing 8.0 \\
\text { triage }\end{array}$ & $\begin{array}{l}\varnothing 8.0 \\
\text { walk }\end{array}$ & $\begin{array}{c}\varnothing 9.0-9.5 \\
\text { triage }\end{array}$ & $\begin{array}{l}\varnothing 8.0 \\
\text { triage }\end{array}$ & $\begin{array}{l}\varnothing 8.0 \\
\text { walk }\end{array}$ \\
\hline 2017 & 5.9 & 77.3 & 16.8 & 17.9 & 60.8 & 21.3 \\
\hline 2018 & 8.9 & 77.9 & 13.2 & 14.2 & 71.5 & 14.3 \\
\hline 2019 & 15.6 & 71.2 & 13.2 & 21.5 & 62.1 & 16.4 \\
\hline $\begin{array}{c}\text { Average by } \\
\text { years }\end{array}$ & 10.1 & 75.5 & 14.4 & 17.9 & 64.8 & 17.3 \\
\hline
\end{tabular}

$\mathrm{T}$ a $\mathrm{b} 1 \mathrm{e} \quad 2$

Peculiarities of formation fractions of corn seed hybrids in regime of sieve separation (2017-2019) [\%]

\begin{tabular}{|c|c|c|c|c|c|c|}
\hline \multirow{4}{*}{ Years } & \multicolumn{6}{|c|}{ Hybrids } \\
\hline & \multicolumn{3}{|c|}{ DN Demetra } & \multicolumn{3}{|c|}{ DN Svitiaz } \\
\hline & \multicolumn{6}{|c|}{ Sieves diameter $[\mathrm{mm}]$} \\
\hline & $\begin{array}{c}\neq 5.5-6.0 \\
\text { triage }\end{array}$ & $\begin{array}{c}\neq 3.75-4.0 \\
\text { triage }\end{array}$ & $\begin{array}{c}\neq 3.75-4.0 \\
\text { walk }\end{array}$ & $\begin{array}{l}\neq 6.5 \\
\text { triage }\end{array}$ & $\begin{array}{c}\neq 4.5-5.0 \\
\text { triage }\end{array}$ & $\begin{array}{c}\neq 4.5-5.0 \\
\text { walk }\end{array}$ \\
\hline 2017 & 14.3 & 69.2 & 16.5 & 19.9 & 55.4 & 24.7 \\
\hline 2018 & 12.1 & 72.7 & 15.2 & 21.5 & 65.6 & 12.9 \\
\hline 2019 & 10.1 & 77.6 & 12.3 & 26.8 & 55.0 & 18.2 \\
\hline $\begin{array}{c}\text { Average by } \\
\text { years }\end{array}$ & 12.2 & 73.2 & 14.6 & 22.7 & 58.7 & 18.6 \\
\hline
\end{tabular}


groups by feature "width of a seed" sieves with round holes which had a diameter $9 \mathrm{~mm}$ (Figure 1) and hybrid DN Svitiaz' - by feature "thickness of a seed" sieves with oblong holes which had size $5.0-5.5 \times 20 \mathrm{~mm}$ (Figure 2), so far as this type-size of sieves divided seed mixture into two practically similar parts $-48.1-51.9 \%$ and $47.7-52.3 \%$ accordingly (Figure 3, 4).

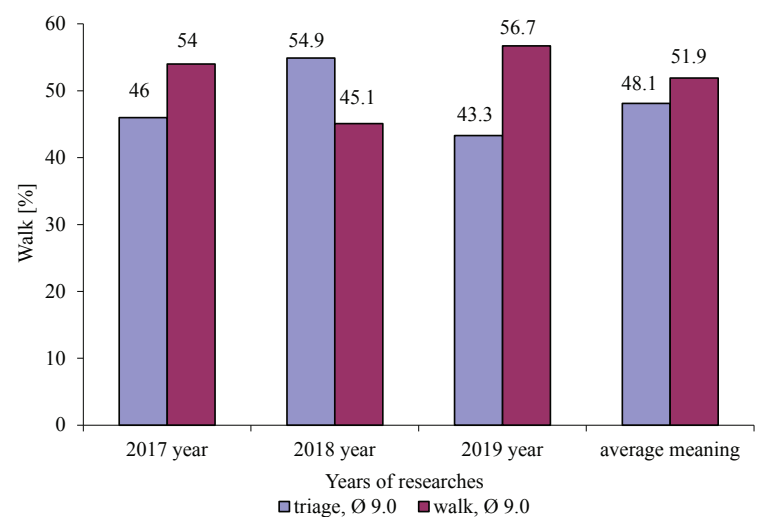

Figure 3. Fractional structure of sowing groups for corn hybrid seed DN Demetra (2017-2019)
At the second stage choice of separate sieves was directly proportional to sieves according to the first stage of the process. So at the first stage sieves with round holes were used, at the second - sieves with oblong holes according to the linear dimension of a seed. For hybrids DN Demetra there were sieves with oblong holes $\neq 3.75-6.0 \times$ $20 \mathrm{~mm}$, and for hybrid DN Svitiaz ${ }^{\prime}$ - sieves with

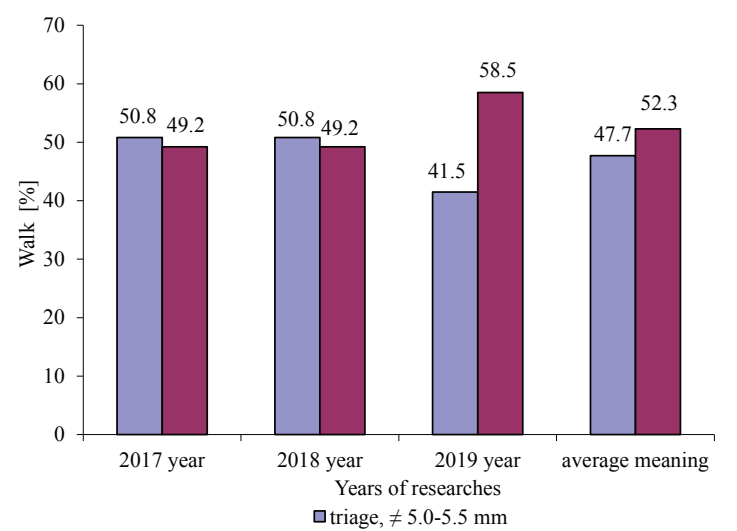

Figure 4. Fractional structure of sowing groups for corn hybrid seeds DN Svitiaz’ (2017-2019)

$\mathrm{T}$ a $\mathrm{b} 1$ e 3

Peculiarities of formation fractions of corn seed hybrids in regime of sieve fractional separation (2017-2019)

\begin{tabular}{|c|c|c|c|c|c|}
\hline \multirow{3}{*}{ Hybrids } & \multirow{3}{*}{ Fraction $[\mathrm{mm}]$} & \multicolumn{4}{|c|}{ Walk of fraction [\%] } \\
\hline & & \multicolumn{3}{|c|}{ Years } & \multirow{2}{*}{$\begin{array}{c}\text { Average } \\
\text { value }\end{array}$} \\
\hline & & 2017 & 2018 & 2019 & \\
\hline \multirow{8}{*}{ 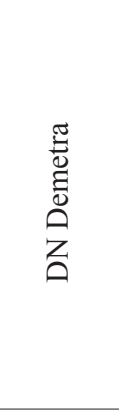 } & \multicolumn{5}{|c|}{ Sowing group I. Ø 9.0 triage } \\
\hline & $\neq 5.00-5.5$ triage & 11.0 & 11.8 & 14.7 & 12.5 \\
\hline & $\neq 3.75-4.0$ triage & 73.0 & 67.8 & 71.6 & 70.8 \\
\hline & $\neq 3.75-4.0$ walk & 16.0 & 20.4 & 13.7 & 16.7 \\
\hline & \multicolumn{5}{|c|}{ Sowing group II. Ø 9.0 walk } \\
\hline & $\neq 5.50-6.0$ triage & 15.7 & 14.2 & 13.8 & 14.6 \\
\hline & $\neq 3.75-4.0$ triage & 66.4 & 69.0 & 71.3 & 68.9 \\
\hline & $\neq 3.75-4.0$ walk & 17.9 & 16.8 & 14.9 & 16.5 \\
\hline \multirow{8}{*}{ 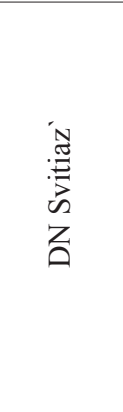 } & \multicolumn{5}{|c|}{ Sowing group $\mathrm{I} . \neq 5.0-5.5$ triage } \\
\hline & $\varnothing 9.0-9.5$ triage & 11.9 & 6.9 & 20.1 & 13.0 \\
\hline & $\varnothing 8.0$ triage & 61.8 & 75.0 & 48.7 & 61.8 \\
\hline & $\varnothing 8.0$ walk & 26.3 & 18.1 & 31.2 & 25.2 \\
\hline & \multicolumn{5}{|c|}{ Sowing group II. $\neq 5.0-5.5$ walk } \\
\hline & $\varnothing 9.0-10.0$ triage & 21.2 & 7.9 & 13.0 & 14.0 \\
\hline & $\varnothing 8.0$ triage & 55.6 & 73.3 & 53.6 & 60.9 \\
\hline & $\varnothing 8.0$ walk & 23.2 & 18.8 & 33.4 & 25.1 \\
\hline
\end{tabular}


$\mathrm{T}$ a $\mathrm{b} 1 \mathrm{e} \quad 4$

Weight of 100 hybrid seeds in dependence on coarse of seeds (2017-2019) [g]

\begin{tabular}{|l|c|c|}
\hline \multirow{2}{*}{\multicolumn{1}{|c|}{ Fraction }} & \multicolumn{2}{|c|}{ Hybrid } \\
\cline { 2 - 3 } & DN Demetra & DN Svitiaz \\
\hline Control & $303.9 \pm 26.3$ & $95.5 \pm 11.5$ \\
$\varnothing 9.0-10.0 \mathrm{~mm}$, triage & $391.3 \pm 6.3$ & $2,333.7 \pm 17.2$ \\
$\varnothing$ 8.0 mm, triage & $310.6 \pm 18.2$ & $301.5 \pm 8.8$ \\
$\varnothing 8.0 \mathrm{~mm}$, walk & $230.6 \pm 17.3$ & $241.6 \pm 7.3$ \\
$\neq 5.5-6.5$ triage & $348.9 \pm 17.1$ & $318.1 \pm 10.7$ \\
$\neq 3.75-5.0$ triage & $305.6 \pm 21.5$ & $293.0 \pm 12.0$ \\
$\neq 3.75-5.0$ walk & $266.5 \pm 22.3$ & $258.1 \pm 9.4$ \\
\hline
\end{tabular}

Note: control - not separated seeds

round holes with diameter $\varnothing 8.0-10.0 \mathrm{~mm}$ (Table 3). Such a methodological approach is explained with optimization of separation and namely taking into account different linear dimensions of a seed.

Basic output of seeds for I and II sowing groups by hybrids formed a so-called medium fraction within

T a b 1 e 5

Weight of 1,000 hybrid seeds in dependence on separation by new methods $(2017-2019)[\mathrm{g}]$

\begin{tabular}{|c|l|l|}
\hline \multirow{2}{*}{$\begin{array}{c}\text { Fractions } \\
{[\mathrm{mm}]}\end{array}$} & \multicolumn{2}{|c|}{ Hybrid } \\
\cline { 2 - 3 } & DN Demetra & \multicolumn{1}{|c|}{ DN Svitiaz } \\
\hline 1 & $303.9 \pm 26.3$ & $295.5 \pm 11.5$ \\
2 & $340.8 \pm 17.7$ & $313.9 \pm 8.0$ \\
3 & $404.7 \pm 17.0$ & $366.5 \pm 10.3$ \\
4 & $347.8 \pm 19.5$ & $325.3 \pm 9.4$ \\
5 & $303.7 \pm 19.4$ & $264.6 \pm 5.4$ \\
6 & $268.9 \pm 17.4$ & $277.3 \pm 6.7$ \\
7 & $316.5 \pm 20.4$ & $328.8 \pm 21.9$ \\
8 & $266.8 \pm 22.1$ & $286.3 \pm 8.2$ \\
9 & $237.5 \pm 21.1$ & $235.7 \pm 9.7$ \\
\hline
\end{tabular}

Note - fractions [mm]

1. Control - not separated seeds Hybrid DN Demetra

2. Sowing group I - triage $\varnothing 9.0$

3 . Coarse - triage $\neq 5.0-5.5$

4. Medium - triage $\neq 3.75-4.0$

5 . Fine - walk $\neq 3.75-4.0$

6. Sowing group II - walk $\varnothing 9.0$

7. Coarse - triage $\neq 5.5-6.0$

8. Medium - triage $\neq 3.75-4.0$

9. Fine - walk $\neq 3.75-4.0$
Hybrid DN Svitiaz triage $\neq 5.0-5.5$ triage $\varnothing 9.0-9.5$ triage $\varnothing 8.0$ walk $\varnothing 8.0$ walk $\neq 5.0-5.5$ triage $\varnothing 9.0-10.0$ triage $\varnothing 8.0$ walk $\varnothing 8.0$
$60.9-70.8 \%$ (triage through sieves $\neq 3.76-4.0 \times 20$ $\mathrm{mm}$ and $\varnothing 8.0 \mathrm{~mm}$ ). While a conditionally coarse fraction with triage from sieves $\neq 5.0-6.0 \times 20 \mathrm{~mm}$ and $\varnothing 9.0-10.0 \mathrm{~mm}$ according to groups and hybrids had practically a similar walk $-12.5-14.6 \%$. A little another pattern was at the fine fraction by hybrids, its walk was almost similar within groups $16.5-16.7 \%$ and $25.1-25.2 \%$.

In process of separation by different methods received fractions were different by physic-mechanical features and quality of seeds. The highest indexes by weight of 1,000 seeds had more coarse fractions which were received by a typical method of separation, as by feature "width of a seed" as by feature "thickness of a seed". The confidence interval affirms it (Table 4).

So coarse fraction with triage from sieves $\varnothing 9.5-10.0 \mathrm{~mm}$ and $\neq 5.5-6.5 \times 20 \mathrm{~mm}$ by hybrids had the highest indexes by weight according to the control had other fractions. The confidence interval was accordingly 54.8 and 9.5 concerning the control of hybrids. During the comparison of the so-called fine fraction by different features of separation, it was established its lowering by weight of 1,000 seeds. But without looking at the lower weight of this fraction confidence interval with the control is confirmed only by feature "width if a seed", namely 30.3 and 34.6 according to hybrids. The confidence interval of a fine fraction and the control by feature "thickness of caryopsis" was confirmed only for hybrid DN Svitiaz'. It can be explained by the more 
rounded shape of the caryopsis for this hybrid. So, during separation by a feature "thickness of a seed", also more coarse seeds and heavier by width seeds got into the fine fraction. It was a reason for the difference with the control.

Seeds of sowing separated groups according to this new method also differed among themselves by features of weight 1,000 seeds (Table 5). Making analyze of these data by features of weight 1,000 seeds, we can affirm that separation by new twostage methods, which has the division of sowing groups, realized by feature "width of a seed" (hybrid DN Demetra) gives the possibility to extract a part of the seeds with a weight of 1,000 seeds which considerably differ from the control. Namely this so-called fine fraction for I and II of sowing groups where the confidence interval is 14 and 35.6 in comparison with a control. However, the index of weight 1,000 seeds by separated variants according to the new method and division of sowing groups was made by "thickness of a seed" had practically similar confidence interval by all fractions in comparison with a control. As an exception was a coarse fraction I of the sowing group and a fine one II of the sowing group. A confidence interval of these fractions was at the level 57.2 and 19.0 according to the control. Based on taken data we can conclude that separation by this new method with feature "width" and "thickness of a seed" gives the possibility to extract fractions with different weights of 1,000 seeds.

By new methods, the biological quality of separated fractions influenced on features of sprouting (Table 6). By features of laboratory germination, it is an established difference between sowing groups and the control. As to sowing fractions of sowing groups, their difference is observed in hybrid DN Svitiaz' because they were taken on the sieves with round holes by feature the "width of a seed", which influences their quality considerably. The positive connection of the seed size on its quality was con-

T a b 1 e 6

Features of sprouting and germinability of hybrids after sieve (fractional) way of separation (2017-2019) [\%]

\begin{tabular}{|c|c|c|c|c|c|c|}
\hline \multirow{2}{*}{$\begin{array}{c}\text { Fractions } \\
{[\mathrm{mm}]}\end{array}$} & \multicolumn{3}{|c|}{ Hybrid } \\
\cline { 2 - 6 } & $\begin{array}{c}|c| \\
\text { Standard- } \\
\text { method }\end{array}$ & $\begin{array}{c}\text { Cold } \\
\text { test }\end{array}$ & Field & $\begin{array}{c}\text { Standard- } \\
\text { method }\end{array}$ & $\begin{array}{c}\text { Cold } \\
\text { test }\end{array}$ & Field \\
\cline { 2 - 6 } & $97 \pm 0.4$ & $98 \pm 0.5$ & $85 \pm 0.9$ & $94 \pm 0.3$ & $86 \pm 0.8$ & $70 \pm 1.7$ \\
2 & $99 \pm 0.6$ & $99 \pm 0.4$ & $87 \pm 0.8$ & $97 \pm 0.6$ & $89 \pm 0.6$ & $75 \pm 1.4$ \\
3 & $99 \pm 0.6$ & $96 \pm 0.5$ & $83 \pm 0.8$ & $97 \pm 0.5$ & $94 \pm 0.9$ & $82 \pm 1.9$ \\
4 & $99 \pm 0.5$ & $97 \pm 0.6$ & $89 \pm 0.7$ & $95 \pm 0.6$ & $90 \pm 0.6$ & $80 \pm 1.4$ \\
5 & $100 \pm 0.4$ & $99 \pm 0.9$ & $88 \pm 1.1$ & $90 \pm 1.0$ & $84 \pm 1.1$ & $69 \pm 2.5$ \\
6 & $99 \pm 0.9$ & $96 \pm 0.9$ & $82 \pm 1.1$ & $89 \pm 1.1$ & $87 \pm 0.7$ & $72 \pm 2.2$ \\
7 & $99 \pm 0.9$ & $95 \pm 0.6$ & $82 \pm 1.3$ & $100 \pm 0.3$ & $96 \pm 1.2$ & $84 \pm 2.4$ \\
8 & $98 \pm 0.5$ & $99 \pm 0.5$ & $81 \pm 0.7$ & $94 \pm 0.8$ & $94 \pm 1.1$ & $82 \pm 2.0$ \\
9 & $98 \pm 0.4$ & $97 \pm 0.9$ & $83 \pm 1.2$ & $90 \pm 0.8$ & $85 \pm 0.7$ & $70 \pm 1.6$ \\
\hline
\end{tabular}

Note - fractions [mm]

1. Control - not separated seeds Hybrid DN Demetra

2. Sowing group $\mathrm{I}-$ triage $\varnothing 9.0$

3 . Coarse - triage $\neq 5.0-5.5$

4. Medium - triage $\neq 3.75-4.0$

5 . Fine - triage $\neq 3.75-4.0$

6. Sowing groupI - walk $\varnothing 9.0$

7. Coarse - triage $\neq 5.5-6.0$

8 . Medium - triage $\neq 3.75-4.0$

Hybrid DN Svitiaz

triage $\neq 5.0-5.5$

triage $\varnothing 9.0-9.5$

triage $\varnothing 8.0$

walk $\varnothing 8.0$

walk $\neq 5.0-5.5$

triage $\varnothing 9.0-10.0$

triage $\varnothing 8.0$

9. Fine - walk $\neq 3.75-4.0$

walk $\varnothing 8.0$ 
firmed by other researches (Kandasamy 2020; Panasiewicz et al. 2008; Enayatgholizadeh et al. 2011; Hunter \& Kannenberg 1972; El-Abady 2015).

By data of a cold test, it is noted a stable tendency of influence features "width of a seed" on its germination. So, the first sowing group of hybrid DN Demetra, separated on the sieves with round holes had higher features of germination in comparison with the control and the second sowing group. Similarly, fractions of hybrid DN Svitiaz' taken by "width of a seed" also had higher features of sprouting according to the control and a fine fraction. Within separated groups on sieves with oblong eyes (hybrid DN Svitiaz') and fractions of seeds within groups (hybrid DN Demetra) germination was practically similar. It is explained that the divi-

$\mathrm{T}$ a

Crop capacity of corn hybrids after sieve (fractional) way of separation

(2017-2019)

\begin{tabular}{|c|c|c|}
\hline \multirow{2}{*}{ Fractions [mm] } & \multicolumn{2}{|c|}{ Hybrid [t/ha] } \\
\cline { 2 - 3 } & DN Demetra & DN Svitiaz \\
\hline 1 & $7.08 \pm 0.4$ & $6.97 \pm 0.3$ \\
2 & $7.96 \pm 0.6$ & $7.19 \pm 0.4$ \\
3 & $7.44 \pm 0.6$ & $7.40 \pm 0.4$ \\
4 & $7.71 \pm 0.6$ & $7.35 \pm 0.4$ \\
5 & $7.60 \pm 0.6$ & $6.72 \pm 0.2$ \\
6 & $7.14 \pm 0.2$ & $6.83 \pm 0.4$ \\
7 & $7.61 \pm 0.6$ & $7.38 \pm 0.2$ \\
8 & $7.01 \pm 0.5$ & $7.08 \pm 0.3$ \\
9 & $7.45 \pm 0.4$ & $6.50 \pm 0.2$ \\
\hline \multicolumn{1}{|c|}{$L S D_{0.05}$ [t/ha] } & & \\
A - for different ways & 0.27 & 0.18 \\
of separation & 0.42 & 0.28 \\
B - for fractions & 0.59 & 0.39 \\
AB - interplay of & 2.79 & 1.95 \\
\hline factors & & \\
\hline \multicolumn{2}{|c|}{ P [\%] } & \\
\hline
\end{tabular}

Note - fraction [mm]:

1. Control - not separated seeds Hybrid DN Demetra

2. Sowing group I - triage $\varnothing 9.0$

3 . Coarse - triage $\neq 5.0-5.5$

4. Medium - triage $\neq 3.75-4.0$

5. Fine - walk $\neq 3.75-4.0$

6. Sowing group II - walk $\varnothing 9.0$

7. Coarse - triage $\neq 5.5-6.0$

8. Medium - triage $\neq 3.75-4.0$

9 . Fine - walk $\neq 3.75-4.0$ sion of seeds by feature "width of a seed" for all its weight. According to features of field germination it was taken data as from the cold test. That is detailed seeds by feature "width of a seed" gave higher figures in comparison with detailed seeds by a feature "thickness of a seed" which only assisted in the leveling of seed material. Besides, we can affirm that method of a cold test is the closest to field conditions, as far as taken data of germination by a cold test and field germination practically coincide. Our statements coincide with the results of our researches (IIbi 2009).

The analogous pattern was by data of yielding capacity within fractional separation (Table 7). Taken yielding capacity of seed for corn hybrids by the researching new method of two-stage fractional separation showed that such seed feature as "width" influenced on its increase. In researched hybrids fractions that were separated on the sieves with round holes and had bigger width of the seed gave higher-yielding capacity comparatively to separated fractions by the thickness of a seed.

So according to received data, we can't affirm unambiguously that process of fractional separation with set in motion sieves with oblong holes assists in an increase of quality for sowing material. By the way increase of yield capacity from sowing more coarse seed was confirmed by other researchers (Kara 2011). But there are other statements that the shape and size of the seed don't influence on yield capacity of corn hybrids in no way (Graven \& Carter 1990; Chaudhry \& Ullah 2001; Hawkins $\&$ Cooper 1979) and otherwise, that fine seeds had better features in comparison with more coarse one (Sulewska et al. 2014; Tabakovic et al. 2020).

The sowing quality of corn hybrid seeds by typical way of separation also increased on the variants where the sieves with round holes were assisted (Table 8). Mathematically it was proved the increase of yield capacity by researching hybrids for conditionally more coarse fractions by feature "width of a seed" according to the control and conditionally fine fractions which were within $0.64-0.88$ and $0.93-1.6 \mathrm{t} / \mathrm{ha}$ accordingly. The analogous tendency was observed in the works of other researchers (Morrison \& Xue 2007; Sleibi 2020). There aren`t mathematical differences within separated fractions 
T a b 1 e 8

Crop capacity of corn hybrids after sieve (calibration) way of separation (2017-2019)

\begin{tabular}{|l|c|c|}
\hline \multirow{2}{*}{\multicolumn{1}{|c|}{ Fractions [mm] }} & \multicolumn{2}{c|}{ Hybrid [t/ha] } \\
\cline { 2 - 3 } & DN Demetra & DN Svitiaz \\
\hline Control & $7.08 \pm 0.4$ & $6.97 \pm 0.3$ \\
$\varnothing 9.0-10.0 \mathrm{~mm}$, triage & $7.96 \pm 0.4$ & $7.82 \pm 0.4$ \\
$\varnothing 8.0 \mathrm{~mm}$, triage & $7.72 \pm 0.4$ & $7.64 \pm 0.2$ \\
$\varnothing 8.0 \mathrm{~mm}$, walk & $6.36 \pm 0.6$ & $6.71 \pm 0.4$ \\
$\neq 5.50-6.5$ triage & $7.56 \pm 0.6$ & $7.21 \pm 0.5$ \\
$\neq 3.75-5.0$ triage & $7.39 \pm 0.5$ & $7.15 \pm 0.2$ \\
$\neq 3.75-5.0$ walk & $6.85 \pm 0.8$ & $7.36 \pm 0.4$ \\
\hline$L S D_{0.05}[\mathrm{t} /$ ha] & & \\
A - for different ways of & 0.31 & 0.28 \\
separation & 0.44 & 0.39 \\
B - for fractions & 0.61 & 0.56 \\
AB - interplay of factors & 2.91 & 2.65 \\
\hline \multicolumn{1}{|c}{ P [\%] } & & \\
\hline
\end{tabular}

Note: control - not separated seeds

by feature "thickness of a seed" and the control that means about their equivalent quality.

\section{CONCLUSIONS}

Separation of the seeds of corn hybrids must be provided by indications of the linear dimension of a seed, coarseness, and weight of 1,000 seeds independence on the regime of separation. The way of division for seed mass by feature "width of a caryopsis" is the most effective. It provides the output of quality seeds. Separation in two-stage the regime with the division of grain mixture provided formation more similar ones by quality seed fraction at the finish stage of a seed-separator work by feature "thickness of a caryopsis". This way is effective for the cleaning-calibration of seeds when its aim is taking out of admixtures and receiving fractions with different linear dimensions.

Most of all, two-stage separation is recommended for corn hybrids which very differ in the shape of a seed and its quality. Such separation can also raise the exactness of division for seed mixtures into fractions and production of seed separators, so the second main stage of separation is realized on partly separated seeds.

\section{REFERENCES}

ABDIPOUR, M. - EBRAHIMI, M. - IZADI-DARBANDI, A. - MASTRANGELO, A.M. - NAJAFIAN, G. - ARSHAD, Y. - MIRNIYAM, G. 2016. Association between grain size and shape and quality traits, and path analysis of thousand grain weight in Iranian bread wheat landraces from different geographic regions. In Notulae Botanicae Horti Agrobotanici Cluj-Napoca, vol. 44, no. 1, pp. 228-236. DOI: $10.15835 /$ nbha44110256.

BRATOEV, K. 2014. Study of the grain mixtures separation process by using of surface mechanical separators - PART I. In International Scientific Journal "Mechanization in agriculture”, vol. 60, no. 1, pp. 16-17.

Catalogue of sorts and hybrids / SE Institute of cereal crops NAAS of Ukraine. 2017. Dnipro, 124 p.

CHAUDHRY, A.U. - ULLAH, I.M. 2001. Influence of seed size on yield, yield components and quality of three maize genotypes. In International Journal of Biological Sciences, vol. 1, no. 3, pp. 150-151. DOI: 10.3923/jbs.2001.150.151.

DEMIN, G.S. - PAVLOVSKIY, G.T. - TELENGATOR, M.A. - TSETSYNOVSKIY, V.M. 1968. Cleaning of seeds at the grain-collecting plants. Moskow: Kolos, $288 \mathrm{p}$.

EL-ABADY, M.I. 2015. Influence of maize seed size/shape, planted at different depths and temperatures on seed emergence and seedling vigor. In Research Journal of Seed Science. vol. 8, no. 1, pp. 1-11. DOI: 10.3923/rjss.2015.1.11.

ENAYATGHOLIZADEH, M.R. - BAKHSHANDEH, A.M. GHARINEH, M.H. - ALAMI SAEID, K.H. - DEHGHAN SHOAR, M. - SHARAFIZADEH, M. 2011. The study of seed source on the S.C704 corn seedling characteristics in laboratory conditions using the cold test. In Australian Journal of Basic and Applied Sciences, vol. 5, no. 12, pp. $557-563$.

ENAYATGHOLIZADEH, M.R - BAKHSHANDEH, A.M. - DEHGHAN SHOAR, M. - GHAINEH, M.H. - ALAMI SAEID, K.H. - SHARAFIZADEH M. 2012. Effect of source and seed size on yield component of corn S.C704 in Khuzestan. In African Journal Biotechnology, vol. 11, no. 12, pp. 2938-2944, DOI: 10.5897/AJB11.2720.

GRAVEN, L.M. - CARTER, P.R. 1990. Seed size/shape and tillage system effect on corn growth and grain yield. In Journal of Production Agriculture, vol. 3, no. 4, pp. 445-452.

HAWKINS, R.C. - COOPER, P.J.M. 1979. Effects of seed size on growth and yield of maize in the Kenya highlands. In Experimental Agriculture, vol. 15, no. 1, pp. 73-79. DOI: $10.1017 / \mathrm{S} 0014479700009224$.

HUNTER, R.B. - KANNENBERG, L.W. 1972. Effects of seed size on emergence, grain yield and plant height in corn. In Canadian Journal of Plant Science, vol. 52, no. 2, pp. 252 256. DOI: $10.4141 /$ cjps72-040.

ILBI, H. - KAVAK, S. - ESER, B. 2009. Cool germination test can be an alternative vigour test for maize. In Seed Science and Technology, vol. 37, pp. 516-519.

KALINIEWICZ, Z. - TYLEK, P. 2019. Aspects of the process of sorting european black pine seeds. In Forests, vol. 10, p. 966. DOI: $10.3390 /$ f10110966.

KANDASAMY, S. - WEERASURIYA, N. - GRITSIOUK, D. - PATTERSON, G. - SALDIAS, S. - ALI, S. - LAZAROVITS, G. 2020. Size variability in seed lot impact seed nutritional balance, seedling vigor, microbial composition and plant performance of common corn hybrids. In Agronomy, vol. 10, p. 157.

KARA, B. 2011. Effect of seed size and shape on grain yield and some ear characteristics of maize. In Research on Crops, vol. 12, no. 3, pp. 680-685. 
KAZAKOV, E.D. 1987. Methods of assessment for seed quality. Moskow: Agropromizdat, $215 \mathrm{p}$.

KYRPA, M.Y. - KOVALOV, D.V. 2018. Ways of seed mixtures separation in process of their after-harvesting treatment (corn as example). In Selection and Seed Growing. Kharkiv, vol. 133, pp. 201-208. DOI: 10.30835/24137510.2018.134379.

KYRPA, M.Y. - SCOTAR, S.O. 2007. Peculiar properties of separation for corn seeds. In Biologic Institute of Grain Farming in UAAS. Dniepropetrovsk, vol. 30, pp. 127-132.

KYRPA, M.Y. - SCOTAR, S.O. 2011. Ways of separation of corn seeds and its quality. In Selection and seed growing. Interdepartmental topical scientific digest. / Institution of plant growing by Uriev V.Y. Kharkiv. Issue 99, pp. 151158. DOI: $10.30835 / 2413-75102011.66080$.

LESNIKOVA, I.U. - KHARCHENKO, E.M. 2002. Basics of work and task problem solving of agriculture in electronic tables of EXCEL. Dniepropetrovsk: Porogy, $147 \mathrm{p}$.

MORRISON, M.J. - XUE, A.G. 2007. The influence of seed size on soybean yield in short-season regions. In Canadian Journal of Plant Science, vol. 87, no. 1, pp. 89-91. DOI: abs/10.4141/P05-209.

PANASIEWICZ, K. - KOZIARA, W. - SULEWSKA, H. 2008. Parameters of vigor tests depending on seed size of some grain cereals. In Fragmenta Agronomica, vol. 1, no. 97, pp. 297-306 (in Polish).

SHEARER, S.A. - MCNEILL, S.G. - WATKINS, G.A. - HIGGINS, S.F. 2000. Grain Drill Calibration Procedures for Winter Wheat. In Agricultural Engineering Extension Publications, vol. 12. Available at: https://uknowledge.uky.edu/ aen_reports/12
SLEIBI, A.T. 2020. Effect of grain size and shape on some characteristics of the development of young stage corn. In EurAsian Journal of Biosciences, vol. 14, no. 1, pp. 659-663.

SOARES, M.M. - OLIVIERA, G.L. - SORIANO, P.E. et al. 2013. Performance of soybean plants as function of seed size: II. Nutritional stress. In Journal of Seed Science [online], vol. 35, no. 4, pp. 419-427. DOI: 10.1590/S231715372013000400002 .

SSTU 4138-2002. 2003. Seeds of agricultural crops. Methods of definition their quality [Effective since $2004-01$ - 01]. Publish. official. Kyiv: Holding the standard override of Ukraine, 173 p. Available at: https://www.twirpx.com/ file/2576304/

SULEWSKA, H. - ŚMIATACZ, K. - SZYMAŃSKA, G. PANASIEWICZ, K. - BANDURSKA, H. - GŁOWICKA-WOŁOSZYN, R. 2014. Seed size effect on yield quantity and quality of maize (Zea mays L.) cultivated in South East Baltic region. In Zemdirbyste-Agriculture, vol. 101, no. 1, pp. 35-40. DOI: 10.13080/z-a.2014.101.005.

TABAKOVIC, M. - SIMIC, M. - STANISAVLJEVIC, R. MILIVOJEVIC, M. - SECANSKI, M. - POSTIC, D. 2020. Effects of shape and size of hybrid maize seed on germination and vigour of different genotypes. In Chilean Journal of Agricultural Research, vol. 80, no. 3, pp. 381 - 392. DOI: 10.4067/S0718-58392020000300381.

TELENGATOR, M.A. - UKOLOV, V.S. - TSETSYNOVSKIY, V.M. 1972. Treatment of grain-crops `seeds. Moskow: Kolos, $271 \mathrm{p}$.

Received: July 14,2020 Accepted: October 29, 2020 